\title{
Ecological Analysis of Disturbance and Disturbance Intensity Estimates for Rainwater Harvesting
}

\author{
Yubang Liu ${ }^{1}$, Chuan Liang ${ }^{2}$, Chengming Ye ${ }^{3 *}$, Jie Xiang ${ }^{4}$

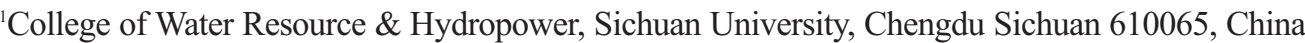 \\ Technology Department, Chengdu University of Technology, Chengdu Sichuan 610051, China \\ ${ }^{2}$ College of Water Resource \& Hydropower, Sichuan University, Chengdu Sichuan 610065, China \\ ${ }^{3}$ Key Laboratory of Earth Exploration and Information Technology of the Ministry of Education, \\ Chengdu University of Technology 610059, China \\ Institute of Mountain Hazards and Environment, CAS, Chengdu Sichuan 610041, China \\ ${ }^{4}$ Chongqing Water Resources and Electrical Engineering College, Chongqing 402160, China
}

Received: 21 January 2014

Accepted: 23 September 2014

\begin{abstract}
From an ecological perspective, the nature of rainwater harvesting with the characteristics of artificial disturbance is a manual disturbance. So it is very important to confirm the degree of ecological disturbance that occurs due to rainwater harvesting. Drawing from ecological disturbance theory, we can utilize both the distance method and dynamic curve method to estimate the level of ecological disturbance and degree of rainwater harvesting with a historical reference point value of the environment as a frame of reference, and with the 20 indicators such as surface runoff and evaluation index. Our examples show that the distance method and dynamic curve method are feasible for evaluating the ecological disturbance degree of rainwater harvesting. There are also research-scale effects in the study of ecological disturbance of rainwater harvesting that embody the comparability of different spatial and temporal ecological disturbance degrees. The comparability of ecological disturbance degrees of rainwater harvesting in an area at different scales or in different areas at the same scales is not strong, but it also generates some useful reference values. The ecological disturbance measurement in the same study area and at the same research-scale at different historical periods can be compared.
\end{abstract}

Keywords: ecological disturbance, rainwater, harvesting, distance method, research scales

\section{Introduction}

As a micro-engineering project, rainwater harvesting has played a major role in solving drinking water and agriculture supplemental irrigation problems while generating ecological improvement in arid regions. This method will

*e-mail: 527101110@qq.com certainly usher in a phase of great development with the utilization of new materials technology combined with rainwater harvesting technology and a myriad of other technologies such as water-saving irrigation techniques [1]. However, rainwater harvesting is achieved through the intervention of the rainfall-runoff hydrological cycle paths and by the change of regional hydrological situations. It is, in essence, an artificial disturbance to the ecology. 
Thus it is very important to determine the degree of ecological disturbance that rainwater harvesting creates. Although the evaluation method for determining the degree of ecological disturbance shows a high level of disruption, it is uncertain whether this method can be used for determining the exact degree of ecological disturbance caused by rainwater harvesting. How does the Ecological disturbance degree change in both spatial and temporal scales? To address these problems, this paper will present an analysis and research initiative.

\section{The Nature and Characteristics of Ecological Disturbance of Rainwater Harvesting}

Rainwater harvesting refers to the regulation of natural rainfall by changing the rainwater hydrologic cycle via engineering technology. It is mainly used to provide such arid and semi-arid lands as hilly areas with both industrial and drinking water through a staggered and limited water supply. Although rainwater harvesting seems benign, it actually is a human-created disturbance to the environment and interferes in the natural rainwater hydrological cycle. It also fits the following description on human disturbance to the environment [2].

1) Geographic concentration and similarity of disturbance. Rainwater harvesting is characterized by regional features and synchronicity due to the influence of physical geography and climate conditions. There is also great similarity in the development and utilization of rainfall.

2) Disturbance durability and profundity influence. Many arid and semi-arid areas have suffered under a drought for a significant period of time, so rainwater harvesting will be a long-term project. For many local residents of these areas, rainwater harvesting is the only way to get potable water for daily use. Continuing to capture large amounts of rainwater, however, will intensify the human disturbance of nature and prevent the local hydrological regime from self-recovery. Furthermore, it could change vegetation distribution and types, soil physicochemical properties, water environments, the atmospheric environment, and human societies in these areas, influencing industry and life in aggregate.

3) Diversity of disturbance. Human disturbance to nature due to rainwater harvesting can be seen in many aspects, such as the application of different storage materials, various places of storage, storage methods, rainwater harvesting modes, and, finally its multi-links and profundity influences.

4) Superimposed effect of rainwater harvesting. The superimposed effect on the natural environment mainly refers to the minor effect of human disturbance activities and the major effect of the full results of those activities. Rainwater harvesting is decentralized and at low magnitude provided we are discussing a single person, village, town, or even area compared with the harvest of rainwater across larger places. However, the impact upon nature can be magnified considerably by geographic concentration, similarity on interference, the areas regional features, synchronicity, etc. Thus a great combined effect of rainwater harvesting is possible if the totality of the disturbance to the larger environment is ignored [3].

As a human disturbance to the environment, rainwater harvesting should have certain limits. And as a process of complex ecosystem evolution, if it is beyond these limits, the deterioration of the ecological environment and even the creation of irreversible changes to the ecosystem would be expected.

\section{Estimation Model and Method for Determining the Degree of Ecological Disturbance Due to Rainwater Harvesting}

The concept and method for determining the degree of ecological disturbance was initially developed from research on a variety of vegetation among a typical forest ecosystem living alongside human beings. It is used to describe the degree to which the pristine vegetation had been disturbed by normal human activities. It may also be said to assess the distance between actual vegetation of a certain site condition and its natural state. In terms of different assessment objectives, the methods for assessing the degree of ecological disturbance are different and include the distance method, the aggregative index number method, the analytic hierarchy process, the model method, relative magnitude method, etc. Among these, the distance method and the dynamic curve method are the most common methods observed [4].

\section{Principles and Steps for Applying the Distance Method to Estimate the Degree of Ecological Disturbance from Rainwater Harvesting}

The distance method is the most commonly used method, and the first to establish a corresponding frame of reference in its natural state. This method provides a baseline from which interference by human beings can be accurately measured so as to compare the actual state of assessed objects with the distance of its frame of reference in its natural state on vegetation levels, site levels, and ecosystem levels. The steps of the distance method are as follows:

1) Collect data in an area to be studied, including information about physical geography, vegetation, soil, climate, history of human activity, and so on.

2) Divide zones and lay sampling sites and perform indicator investigation statistics.

3) Design a Hemeroby table. Divide corresponding interference gradations of different intensities for human impact from weak to strong and provide corresponding gradation values.

4) Estimate the degree of ecological disturbance and existing elements in sample plots. First, estimate the relative value of ecological disturbance for each element. This estimation is done in terms of the distance between the state of the actual measurement of each element and the "potential natural vegetation." Then, according to each 
element's degree of relative materiality, create a synthesis of weight estimate for the degree of ecological interference relative to the values of all elements to get a total relative value measurement for ecological disturbance. Refer to the ecological disturbance degree table according to the sample plot's total relative values so the sample plot's natural state measurements can be determined [5]. The formula for this measurement is as follows:

$$
R E F D=\sqrt{\left(1-x_{1 j}^{\prime}\right)^{2} w_{1}+\left(1-x_{2 j}^{\prime}\right)^{2}+\cdots+\left(1-x_{n j}^{\prime}\right)^{2} w_{n}}
$$

...where REFD is disturbance degree; $x_{n j}^{\prime}$ is variable values after processing of relativization; $x_{i j}^{\prime}=x_{i j} / x_{i o}, i$ is evaluating indicator, $i=1,2 \ldots, n ; j$ is $j$ evaluating zone, $j=1,2 \ldots, m$; $x_{i j}^{\prime}$ is $i$ 's actual value of evaluating indicator in $j$ evaluating zone, $x_{i o}$ is $i$ indicator standard value in target zone; weight $w_{j}$ is the corresponding weight in terms of importance by degree of different evaluating indicators that have played in the process of the total accumulated disturbance.

Evaluating principles are: if $R E F D$ value is smaller and closer to the target value, it shows that the accumulating disturbance degree is weaker; if the REFD value is bigger and farther from the target value, it shows that the accumulating disturbance degree is stronger; while doing relativization processing for positive indicators we use the actual value in preference to the standard value; for negative indicators, use the standard value rather than the actual value.

As a man-made disturbance, the disturbance of harvesting rainwater on the natural ecological environment creates problems such as time interference, intensity interference, and frequency interference. The above-stated evaluation method can be used to estimate the degree of ecological disturbance generated by rainwater harvesting and its impact on the natural ecological environment.

\section{Applying the Distance Method to Determine the Degree of Ecological Disturbance Caused by Rainwater Harvesting}

The key to applying the distance method to estimate the degree of ecological disturbance is how to find a proper frame of reference to view the target land in its natural state. First, this frame of reference may be areas of pristine forests never touched by humans. Next, this frame may be natural areas seldom disturbed before the Industrial Revolution at the beginning of the $19^{\text {th }}$ century and contain a relatively rich variety of vegetation and structure. But actually it is difficult to find standing forest or natural vegetation that remains in an undisturbed natural state and that can be used as a proper frame of reference. Therefore, Tuexen thinks that since it is very difficult to find a proper frame of reference for land as it existed in the past, we may as well establish a "future" frame of reference starting from the present site to evaluate the total impact human beings have ever had on vegetation and/or evaluate the dis- tance between the actual state of vegetation and the "future" estimate for a balanced state. Using this train of thought as a reference and based on the developmental features of periodicity for the use of rainwater harvesting, a relatively smaller time point may be found as a relative frame of reference with a small scale of rainwater harvesting ever having been historically attempted and thus having had little disturbance on the natural ecological environment. The degree of ecological disturbance can be calculated by using the distance method. The impact on the amount of water in the local environment, soil environment, biotic environment, atmospheric environment, economic environment, and social environment caused by the process of rainwater harvesting can be measured by twenty separate impact indicators such as the runoff coefficient and distance method. Thus the Hemeroby value and rainwater harvesting impact can be calculated. (See Table 1 for processed targeted value).

\section{Observations of Change of Humidity, Evaporation, and Soil Moisture after Rainwater Harvesting \\ Based on the Dynamic Curve Method}

1) The humidity of a normal year maximum, minimum, and average can be determined by making Jianyang field observation of humidity averages accounting for 1-12 months where no rainwater harvesting has historically occurred. After this, we draw dynamic curves and make a comparison of the average field observation for humidity in rainwater harvesting years to one in which no harvesting has occurred to assess the strength of the disturbance on field humidity (Fig. 1).

2) We can take the average field evaporation measurement every morning from 5:20 a.m. to 5:20 p.m. during nonharvest years in Jianyang and make a comparison to other years during which rainwater harvesting occurred in Jianyang to assess the total disturbance on field evaporation due to rainwater harvesting (Fig. 2).

3) We can take the average surface soil moisture (under 20 $\mathrm{cm}$ ) during non-harvest years in Jianyang and make a comparison to other years during which rainwater harvesting occurred in Jianyang to assess the total disturbance on surface soil moisture due to rainwater harvesting (Fig. 3).

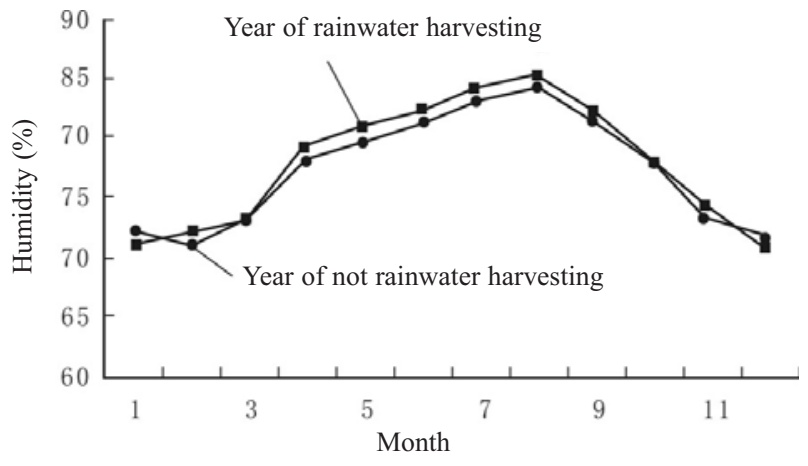

Fig. 1. Comparison of the dynamic curve of atmospheric humidity in the field. 


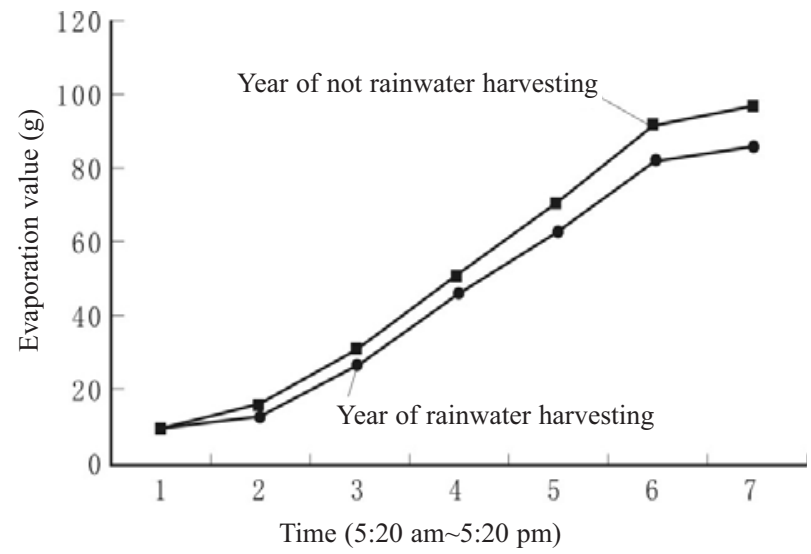

Fig. 2. Comparison of field evaporation dynamic changes.

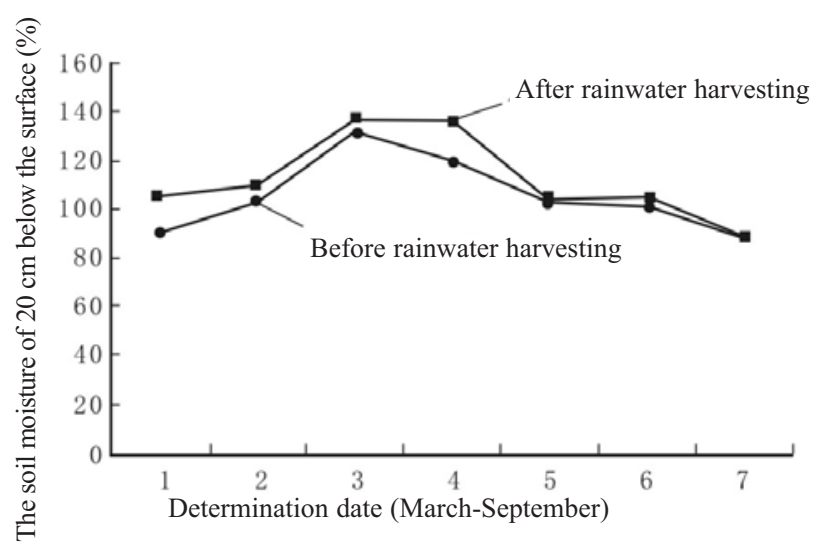

Fig. 3. Comparison of soil moisture dynamic changes of $20 \mathrm{~cm}$ below the surface.

\section{Example of Estimating Ecological Disturbance of Rainwater Harvesting and Its Comparability}

\section{Example of Estimating Ecological Disturbance Degree of Rainwater Harvesting}

\section{Introduction to the Study Area}

Ziyang city lies in the center of Sichuan Basin, and is 88 kilometers wide with Chengdu and Deyang on the north, connecting to Neijiang in the south, Chongqing and Suining in the east, and Meishan in the west. It has an area of 7,962 $\mathrm{km}^{2}$ and a population of 3,660,100. Ziyang has a tropical monsoon climate, with an average annual precipitation of $1,100 \mathrm{~mm}$, an average temperature of $17^{\circ} \mathrm{C}$, sunshine for 13 hours, and a frost-free period of 300 days. It has a typical basin climate with significant characteristics of a transitional climate. It is a place with heavy air humidity, small temperature differences between day and night, low wind speeds, and foggy days all year round. There are frequent droughts in this place; especially common are dry winters, and spring droughts and autumn droughts are as high as $90 \%, 75 \%$, and $75 \%$. In Ziyang, the landform is dominated by hills, accounting for over $90 \%$ of the region, and the local soil contains brown purple soil and rich mineral resources [6].

\section{Estimations of the Degree of Ecological Disturbance Caused by Rainwater Harvesting}

Results on the degree of disturbance in 1985, 1990, 1995, 2000, and 2005 are calculated by applying examples based on the index value of 1983 of Ziyang city.

Results are shown as Table 1 after the relative processing of indexes; the weight of each index can be calculated using the entropy method and results are as follows:

$w_{1}=0.067825146, \quad w_{2}=0.047556762, \quad w_{3}=0.06305625$, $w_{4}=0.042556821, \quad w_{5}=0.045813489, \quad w_{6}=0.051735421$, $w_{7}=0.051096943, \quad w_{8}=0.051759215, \quad w_{9}=0.047322888$, $w_{10}=0.048888, \quad w_{11}=0.053302497, \quad w_{12}=0.055358287$, $w_{13}=0.043181529, w_{14}=0.043146991, w_{15}=0.043016167$, $w_{16}=0.068195301, w_{17}=0.039644792, w_{18}=0.048493869$, $w_{19}=0.047234382, w_{20}=0.040815238$

We may calculate the ecological disturbance degree of rainwater harvesting in each year in accordance with formula (1) and the results are shown in Table 2 and Fig. 4.

From Fig. 5 it can be seen that the degree of ecological disturbance due to rainwater harvesting in the environment is increasing year by year along with the expansion of rainwater harvesting scales and enhancement of the application of rainwater harvesting. In the mid 1990's the scale grew in almost a straight line, which is in agreement with the Ziyang situation.

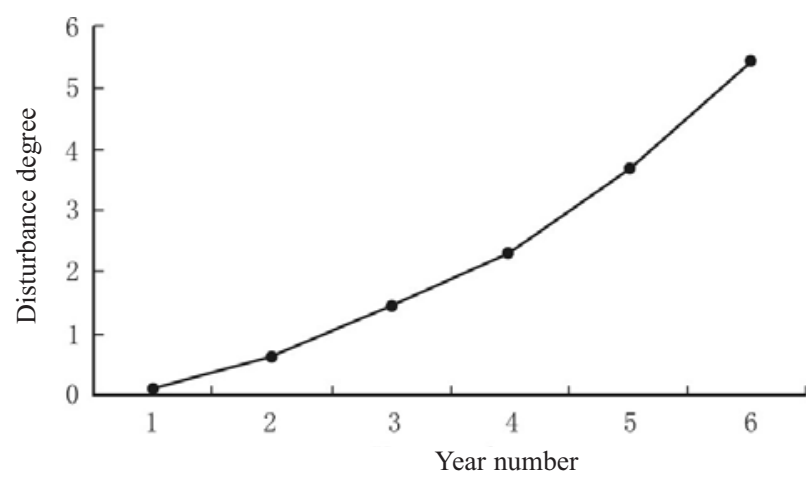

Fig. 4. The trend of the degree of disturbance brought about by rainwater harvesting of Ziyang in 25 years obtained by application examples.

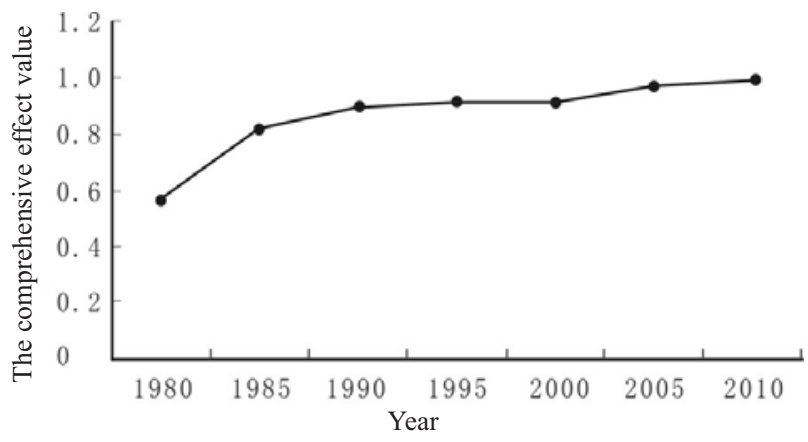

Fig. 5. The changing trend of environmental effects of Ziyang in 25 years obtained by cusp catastrophic model. 
Table 1. Relative deal value of the original value of each index.

\begin{tabular}{|c|c|c|c|c|c|c|c|}
\hline \multirow{2}{*}{ Index Name } & \multirow{2}{*}{$\begin{array}{c}\text { Standard } \\
\text { values (83) }\end{array}$} & \multicolumn{6}{|c|}{ Year } \\
\hline & & 1985 & 1990 & 1995 & 2000 & 2005 & 2010 \\
\hline Per capita income & 340.34 & 1.35 & 2.49 & 5.77 & 8.31 & 12.22 & 18.33 \\
\hline Per capita food & 0.38 & 1.13 & 1.79 & 1.97 & 2.53 & 3.05 & 4.97 \\
\hline Economic efficiency & 0.9 & 1.06 & 1.58 & 1.92 & 2.43 & 6.08 & 6.72 \\
\hline Runoff coefficient & 0.31 & 1.13 & 1 & 1.16 & 0.94 & 1.10 & 1.16 \\
\hline Groundwater exploitation rate & $50.60 \%$ & 0.99 & 0.96 & 0.92 & 0.89 & 0.84 & 0.80 \\
\hline Runoff sediment concentration & 1.65 & 0.99 & 0.98 & 0.75 & 0.61 & 0.62 & 0.59 \\
\hline Surface Water Quality Index & 3 & 1 & 1 & 0.67 & 0.67 & 0.67 & 0.67 \\
\hline Soil erosion area ratio & $75.75 \%$ & 0.99 & 0.94 & 0.83 & 0.72 & 0.63 & 0.53 \\
\hline Soil erosion modulus & $3,747,000$ & 1 & 0.99 & 0.96 & 0.87 & 0.78 & 0.66 \\
\hline Sloping ratio & $26.00 \%$ & 1 & 0.96 & 0.85 & 0.73 & 0.69 & 0.69 \\
\hline Forest coverage & $6.20 \%$ & 1.03 & 1.44 & 2.22 & 2.97 & 4.51 & 5.55 \\
\hline Plantation coverage & $2.08 \%$ & 1.13 & 2.88 & 3.93 & 6.08 & 7.88 & 10.49 \\
\hline Average annual temperature & 17.10 & 1.09 & 1.13 & 1.06 & 1.05 & 0.87 & 1.04 \\
\hline Annual evaporation & 765.6 & 1.00 & 1.03 & 1.03 & 1.01 & 1.01 & 1.03 \\
\hline Average annual humidity & $73.42 \%$ & 1.03 & 1.03 & 1.07 & 1.00 & 1.01 & 1.04 \\
\hline Annual precipitation & 852.9 & 1.07 & 1.05 & 1.08 & 1.02 & 1.07 & 1.11 \\
\hline Population and livestock & 426.97 & 1.14 & 1.23 & 1.30 & 1.37 & 1.44 & 1.60 \\
\hline Engel coefficient & 0.535 & 0.93 & 0.92 & 0.86 & 0.74 & 0.77 & 0.67 \\
\hline Catchment degree & $7.37 \%$ & 1.00 & 1.48 & 1.85 & 2.55 & 3.49 & 3.96 \\
\hline Land production potential & $11.10 \%$ & 1.02 & 1.16 & 1.19 & 1.27 & 1.32 & 1.31 \\
\hline
\end{tabular}

The original data values in the table are taken from the Statistical Yearbook of Sichuan Province, Sichuan Agricultural Statistics Yearbook, since the survey data.

Table 2. The comprehensive disturbance degree of rainwater harvesting in each year calculated by application examples.

\begin{tabular}{|c|c|c|c|c|c|c|c|}
\hline Year & 1983 & 1985 & 1990 & 1995 & 2000 & 2005 & 2010 \\
\hline$R E F D$ & 0 & 0.112355 & 0.614588 & 1.466029 & 2.3094 & 3.6606 & 5.3538 \\
\hline
\end{tabular}

\section{The Comparability and the Spatial and Temporal \\ Scales of Ecological Disturbance Degree of Rainwater Harvesting}

The spatial and temporal scale is also a difficulty in estimating the degree of ecological disturbance as well as researching the ecology. Therefore, nature should be correctly understood on the premise that research in natural science is carried out in an accurate manner. Although the medium scale of disturbance accounts for most and is accepted by the public, it is still ambiguous and hard to quantify for various landscapes and ecosystems. The awareness of acceptable scales within which people can conduct activities in different ecosystems is absent from their minds as they go about their daily activities [7].
The spatial scale is also of great significance in measuring the degree of ecological disturbance, and is mainly reflected by the comparability of the disturbance value measured in different regions and at different times. Thus the disturbance degree seen in various scales cannot be neatly compared with others, for the environmental effects of rainwater harvesting vary according to the spatial scales. In various regions, there is still no comparability of the degree of disturbance in the same scales because of the presence of diverse environmental effects. For multi-stage rainwater harvesting spatial scales in one region may not match exactly, although the disturbance degrees are comparable [8].

Based on Figs. 5 and 6, we can know that both the degree of disturbance and the environmental impact consistently grow in tandem with each other, which means that 


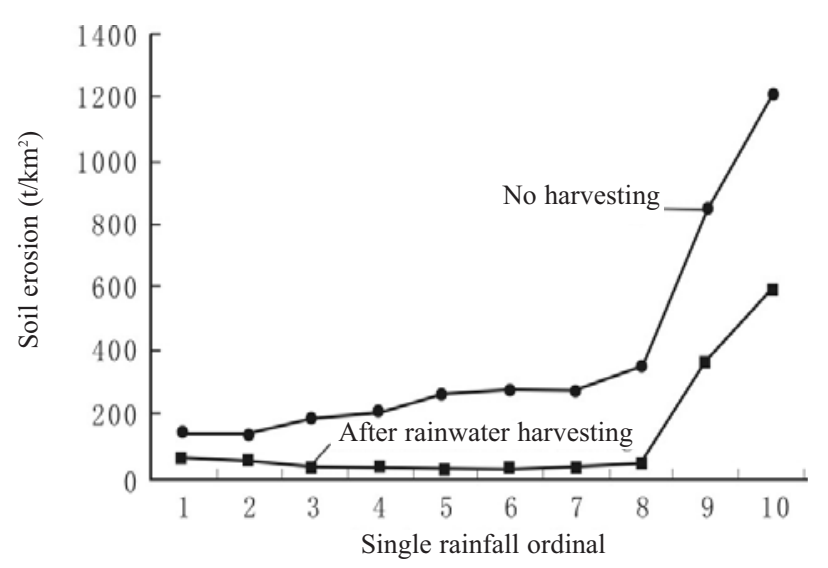

Fig. 6. Change of soil erosion after the rainwater harvesting.

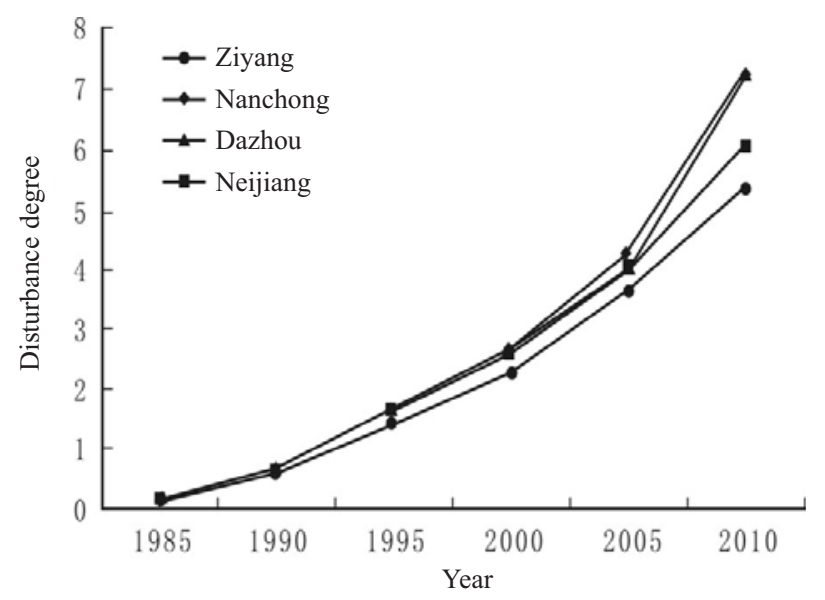

Fig. 7. The degree of ecological disturbance and changes brought about by rainwater harvesting in Ziyang, Neijiang, Dazhou and Nanchong in 25 years calculated by application examples.

application examples are feasible for estimating the disturbance degree, even though the growth rate and curves are not the same. Fig. 7 shows the degree of difference of ecological disturbance for rainwater harvesting with the same spatial scales in different regions, which supply a reference and basis for the application.

\section{Conclusions}

1) From an ecological perspective, the essence of rainwater harvesting with the general characteristics of artificial interference is artificial disturbance.

2) In ecology there are many ways to calculate the degree of ecological disturbance, including the distance method, which is the most commonly used method and also can also be used to estimate the degree of ecological disturbance of rainwater harvesting. The critical applications of the distance method to estimate the degree of ecological disturbance brought about by rainwater harvesting is to find a natural frame of reference to act as a baseline for future measurement. However, in practice this is difficult to find. According to the development stage characteristics of rainwater harvesting, the background value of a historical point of reference for rainwater harvesting may be selected as the reference standard. Meanwhile, 20 indicators (such as surface runoff) may be selected as evaluation criteria for the degree of ecological disturbance of rainwater harvesting. The results of a case study making Ziyang city in Sichuan province as an example show that this method is feasible.

3) There are also research-scale effects coming from the study of the degree of ecological disturbance caused by rainwater harvesting that embody the comparability of the degree of different spatial and temporal ecological disturbances. The comparability of the degree of ecological disturbance of rainwater harvesting in areas at different scales or in different areas at the same scales is not strong, but it also provides some reference value. The degree of ecological disturbance in the same study area at the same research scale in different historical periods can be compared.

\section{Acknowledgements}

This work was supported by the National Natural Science Foundation of China (grant No. 41271045), National 973 Project (grant No. 2013CB036401), and the National Natural Science Foundation of China (41001253) and Chinese Postdoctoral Science Foundation (2012M521717).

\section{References}

1. ZHAO W.J., LI Z.L., FAN Y.W., SUN W. Models of Rainwater Harvesting System and Sustainable Development Countermeasures in Arid and Semi-arid Areas. Research of Agricultural Modernization. 32, (5), 623, 2011.

2. WANG C. Rationality of Natural Disturbance from Human Disturbance. Jilin Forestry College. J. 14, (4), 223, 1998.

3. ZHU J.J., LIU Z.G. Ecological Studies of Forest Disturbance. J. Appl. Ecol. 15, (10), 1703, 2004.

4. JOHNSON E.A., MIYANISHI K. Plant Disturbance Ecology: The Process and the Response. Elsevier, USA, 2007.

5. SONG J.X., LI HE., LI Q. Urban Rainwater Resources and Ecological Environment Effects. J. Ecol. 22, (2), 32, 2003.

6. Ziyang Government Network. Ziyang Introduction [EB/OL]. [2014-03-05]. http://www.114huoche.com/zhengfu_ZiYang.

7. YU L.Z., ZHU J.J., ZHANG Y.H. Evaluation of Forest Disturbance. Chinese Journal of Ecology. 28, (5), 976, 2009.

8. LI CX. On the hydrological basin scale and similarity. J. Hydraul. Eng.-ASCE (1), 40, 1995. 